\title{
Comparative study of traditional and contemporary Islamic dwelling design: the case of Benghazi, Libya
}

\author{
N. Ali, A. Taki \& B. Painter \\ School of Engineering and Sustainable Development, De Montfort \\ University, UK
}

\begin{abstract}
In Benghazi, Libya, the rising population and increased housing demand has led to high energy consumption in order to provide comfortable conditions. These contemporary dwellings make use of outdoor open spaces and a high glazing ratio of the building envelope, leading to significant underperformance with respect to heat gains and cooling loads when compared with more traditional dwellings. The aim of this paper is to investigate the main features of traditional Islamic houses, which can enhance environmental comfort and reveal insights when compared with contemporary houses. The methodology will consist of reviewing previous research regarding traditional Islamic houses in order to find the main climatic features, as well as a case study that will involve evaluating contemporary houses in Benghazi, Libya. Furthermore, 60 questionnaires were distributed in order to determine the main problems relating to both residents and housing design in terms of enhancing housing thermal comfort and decreasing energy consumption. The comparative study shows that the majority of traditional Islamic houses have sustainable features that can be integrated into contemporary houses in order to provide thermal comfort whilst minimising energy consumption. These features include internal open spaces (such as courtyards), and small, high openings in the external façade, together with shading devices and specific building orientation. The research likewise shows that 89 percent of contemporary Islamic houses in Benghazi not only lack these sustainable features as internal open spaces, but also shows that all of the local residents depend on air conditioning when facing the hot days. Additionally, the survey illustrates that just 15 percent of architects are responsible for designing these houses, which have windows with a high glazing ratio, located in the façades most exposed to the sun. The implication of this with
\end{abstract}


regards to the sustainable designing of contemporary Islamic houses is discussed in order to help produce guidelines for designers that would respond to both the climate and to local people's needs.

Keywords: hot climate, thermal comfort, privacy, traditional Islamic houses, contemporary houses, energy consumption, Libya.

\section{Introduction}

Traditional Islamic dwellings are organized around an interior courtyard protected from the outside with simple walls to assure privacy. This arrangement enables the control of indoor temperature [1] while respecting the need for privacy. With this purpose, windows are placed in the courtyard to bring natural light and air inside the house [2]. As a result of the Italian colonization, a new housing design policy was issued. However, this imported housing model has not met the socialcultural requirements of an Islamic country [3]. After 1969, the Libyan government started to construct new and large housing projects in order to meet the increasing demand for houses, but without understanding the social-cultural needs and climate conditions in Libya. Although privacy is one of the more important requirements in Islamic houses, it is ignored in most contemporary house designs [4-6]. Furthermore, Khalaf [7], Ajaj and Pugnaloni [8], Khoukhi and Fezzioui [9] and Leylian et al. [10] indicate that contemporary Islamic houses lack natural climate control because no studies were conducted on the impact of microclimates on the building form.

\section{Thermal comfort in traditional Islamic architecture in hot climates}

Traditional Islamic architecture offers useful examples to contemporary architecture, especially in those countries with hot climate. The thermal comfort principles will be demonstrated by examining traditional Islamic houses [8].

\subsection{Orientation}

It is beneficial to have sunlight in a house, without having the damaging effects of extreme temperature and glare. Living spaces are organized around the courtyard taking into account their relationship with the orientation of the sun during the seasons (Figure 1) [11].

The sun projection angles change at different times throughout the seasons, with a different degree of solar penetration in the spaces of the house. Therefore, the best orientation for courtyards is on the east-west axis, with the longitudinal elevation being to the north, for the following reasons:

- The sunlight projection is towards the longitude elevation - for example, south.

- The south elevation receives the largest amount of heat in winter and the least in summer [11]. 


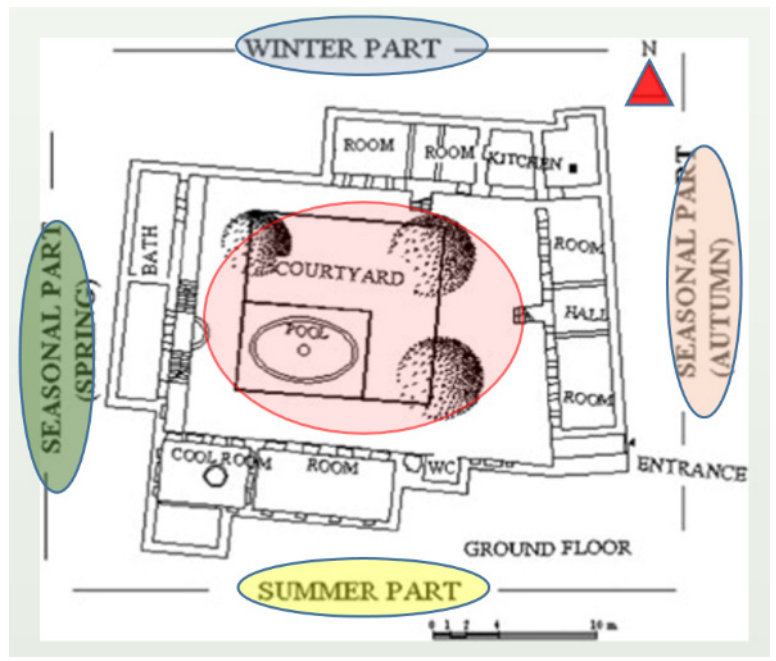

Figure 1: Different spaces for the family according to the direction of the sun, ground floor plan of a home in Diyarbakir.

\subsection{Natural ventilation}

Passive cooling is achieved in traditional Islamic architecture by means of natural ventilation, which enhances the indoor climate by evaporative cooling. In addition, the orientation of traditional houses takes into account the prevailing winds and sunlight. Thus, solid opaque façades are oriented in a way to protect the outdoor living zones from the hot winds, while allowing sufficient winter sunlight to enter the living areas. The main natural ventilation elements are wind towers, or malqafs. The design of these wind towers can facilitate airflow in the rooms [12]. The different temperatures between solid and void elements cause wind circulation. Besides, there are differences in air density that contribute to air circulation:

- Between the interior courtyard and the exterior space.

- Between the courtyard and the interior spaces of the building.

Also, wind-cooling can decrease day-time surface temperatures, which then benefits the night-time conditions [11]. Additionally, openings and windows are essential for natural lighting and ventilation. However, in the summer, the absence of any openings helps to minimize heat gain, especially on the west side. For that season, openings should be shaded from direct sunshine and placed high on the walls in order to be away from ground rays [8].

\subsection{Shading}

Solar radiation is a major source of heat gains in a building. Adequate shading decreases air temperature, radiant heat, and glare effectively. The most commonly 
used building elements to produce shading are protrusions and cornices on the outer façades, as well as on the inner courtyard walls [8]. Furthermore, another important device for providing shading is "Mashrabiya", an enclosed window with an engraved wooden lattice located on the second floor of a building. Essentially, Mashrabiya can reduce solar radiations by:

- Controlling the passage of light.

- Controlling the air flow.

- Decreasing the temperature of the air current.

- Increasing the humidity of the air current, and

- Ensuring privacy.

Besides, there is an aesthetically pleasant effect produced by the light passing through the balusters of the enclosed window [8].

\section{Problems with contemporary houses}

\subsection{Housing design changes}

Traditional houses are often well adapted to local climatic and environmental conditions, including the socio-cultural ones. In spite of all these benefits, however, most of the features of traditional houses have disappeared in contemporary housing developments in Islamic countries. Many cultural and traditional architectural features were abandoned to adopt new ways of life [5]. Most Islamic countries, including Libya, have experienced a rapid growth in their economy, accompanied by an increase in population. These changes resulted in an increase of modern houses, which were influenced by western designs. In other words, the designs of modern houses have changed, heading away from the traditional houses which were adapted to the socio-cultural and environmental conditions [13]. Contemporary housings have been built in high-rise blocks and also single-family detached homes [14]. Most buildings in large cities, including Benghazi, are residential houses, which represent 40.61 percent of the building stock.

Most of these houses have adopted western models. For example, outdoor spaces can be seen in the modern villas instead of the traditional inner courtyards; large glazed windows are used instead of high, small openings, and concrete and steel are employed instead of the traditional building materials [15]. During different stages of the architectural development of Islamic countries, the disappearance of traditional house characteristics was a consequence of the shift in housing design practice. Nowadays, the houses are re-oriented to the street and have become less responsive to the residents' needs in terms of privacy and thermal comfort. In the traditional houses, residents had enough privacy to use the inner spaces organized around an open and sheltered central courtyard; in contemporary houses, the outer spaces exclude the residents [5]. In fact, most of the outdoor spaces - such as balconies, verandas, and gardens - are not effectively used because they do not provide privacy, and with time, they have become nonfunctional spaces [16]. 


\subsection{Energy consumption}

El-Shorbagy [1] indicated that climate acts as a complementing and moderating factor for a society whose cultural and religious traditions demand privacy. Therefore, it is important to consider the climate role in Islamic architecture in this cultural context. Local climate and energy consumption are mostly ignored in contemporary housing designs. A rise in indoor temperature has led to the use of air conditioners, which contributed to an increase in energy consumption for cooling, heating and water heating, with the corresponding increase of $\mathrm{CO}_{2}$ emissions [15]. According to the UN Statistics Division/CDIAC, in terms of carbon dioxide emissions, Libya ranks 11th among countries in the world, with 1.98 tons of carbon dioxide emissions per capita. This is higher than the global average of 1.13 tons per year [15]. In addition, because of the rapidly growing demand for electric power, power cuts are common. Moreover, the demand is increasing rapidly, at a rate of about 6-8 percent per year. For example, in 2002, the demand for electricity reached 13.414 billion $\mathrm{kWh}$, while in 2010, it was 5.8 $\mathrm{GW}$, and it is expected to be $8 \mathrm{GW}$ by 2020 [15]. Therefore, there is a need to study, investigate, and try to find solutions to reduce the energy consumption. With this aim, this research will focus on residential buildings as they consume the highest amount of electricity. According to the General Electric Company of Libya (GECOL), the highest energy consumption comes from houses, with the energy being used for cooling, heating, and water heating, making up 39 percent of Libya's total energy consumption [17].

\section{Aim and methodology of the research}

In our research work, we have investigated contemporary housing in Libya, in particular their relationship with the inhabitants' needs and the socio-cultural and climatic factors. Contemporary house designs in Benghazi have been analysed, using the results of the study as guidelines to be used in the design of sustainable houses in other Islamic cities with the same climate. The research focused on the level of comfort provided by the dwellings, in order to identify the requirements of users. A multi-method approach was adopted to analyse the relationship between comfort and housing design in hot climates. Previous research on traditional Islamic housing was reviewed in order to identify its main features. In addition, contemporary houses in Benghazi were investigated to determine how the main architectural design elements affect the thermal comfort and energy consumption. To support the research, a survey has been conducted to know occupants' opinions about comfort, as well as their views with regard to their general satisfaction regarding contemporary private housing in Benghazi. The survey was divided into five sections: general information, house information, house design, house elevations, and cooling demand. It was randomly distributed in two neighbourhoods, to both residents of multi- and single-family housing. Out of the 60 surveys ( 30 for apartments and 30 for the houses), 51 completed questionnaires were returned ( 24 and 27 , respectively). 


\section{Benghazi background}

According to the projections of the Libya National Statistics Office (LNSO), Benghazi has a population of 631,555 inhabitants with a density of 2,000 inhabitants per square kilometre, the highest in Libya [18]. Benghazi is a magnet for the migrants coming from different regions of the country - from the south, east, and even from the west - due to its vigorous economy. This situation has led to a population growth and an increased demand for housing. According to the National Physical Plan, the yearly housing demand will steadily grow from 24,000 to 38,000 units between 2000 and 2025 [19]. This increase in housing construction is offset by an increase in the use of air conditioning, which leads to energy consumption and the emission of carbon dioxide. According to GECOL, houses in Benghazi are responsible for the majority of energy consumption, with residential buildings consuming 36 percent of the total energy in 2012 [17]. The houses in Benghazi are lacking appropriate design features and are less resilient to hot climatic conditions. Besides, these houses fail to meet the social requirements, such as the need for privacy [20]. Therefore, it is necessary to find alternative ways to create a sustainable built housing environment [21].

In Benghazi, contemporary housing types can be classified into apartments and private houses (terraced houses or villas). According to the National Census (NSA) and the Benghazi Planning Study conducted by El-Emara Engineering Consultants, the majority of houses (60.5 percent) are private houses (villas and terraced houses), with villas being the preferred model by most residents [19]. Dwellings have a distinguished exterior form, but no relationship to the interior spaces and no consideration for the orientation. For instance, as shown in Figure 2 , windows are directed to the outdoor space rather than to the inner courtyard. In traditional architecture, however, the courtyard is placed at the center to foster both family life and climatic control.

Furthermore, modern houses let a greater amount of solar radiation pass through the exterior façades due to the large glazed windows, regardless the orientation. These design solutions are not appropriate for this climate. Thus, windows in Benghazi houses have two negative impacts, from the social and climatic points of view. In addition, many verandas and balconies in modern houses are closed, used for storage, or are not used at all since they lack the required privacy.

\section{Survey analysis}

\subsection{House design}

\subsubsection{Open spaces}

Regarding the location of open spaces in villas (indoor, outdoor, or both), 89 percent feature an outdoor open space, while 7 percent have both kinds and just 4 percent have only indoor open spaces. Concerning the use of these spaces (as shown in Figure 3), all open spaces are used for parking, with the highest percentage of use being for play areas, storage, and seating areas, with 85 percent, 


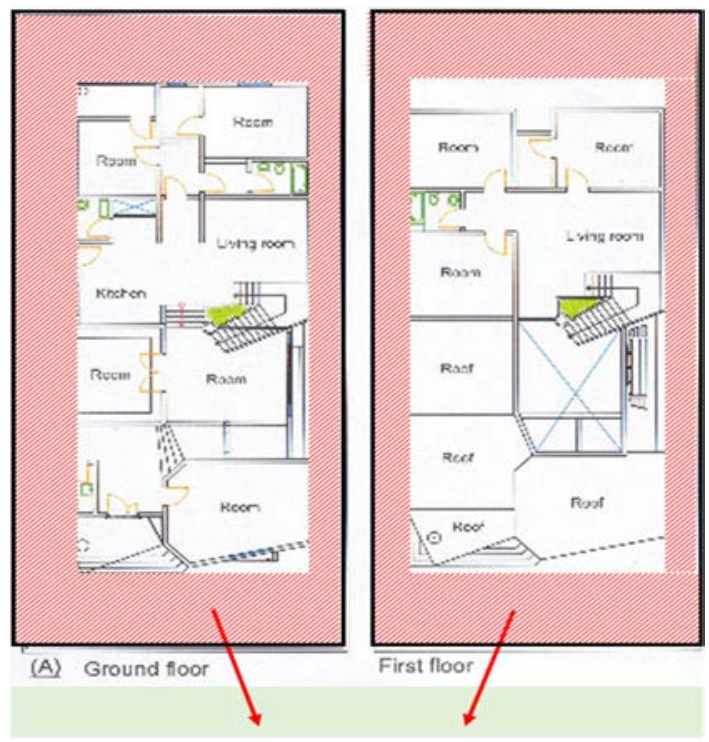

Use of outdoor open space does not consider orientation.

Figure 2: Plan of a private house with outdoor open space surrounding the building.

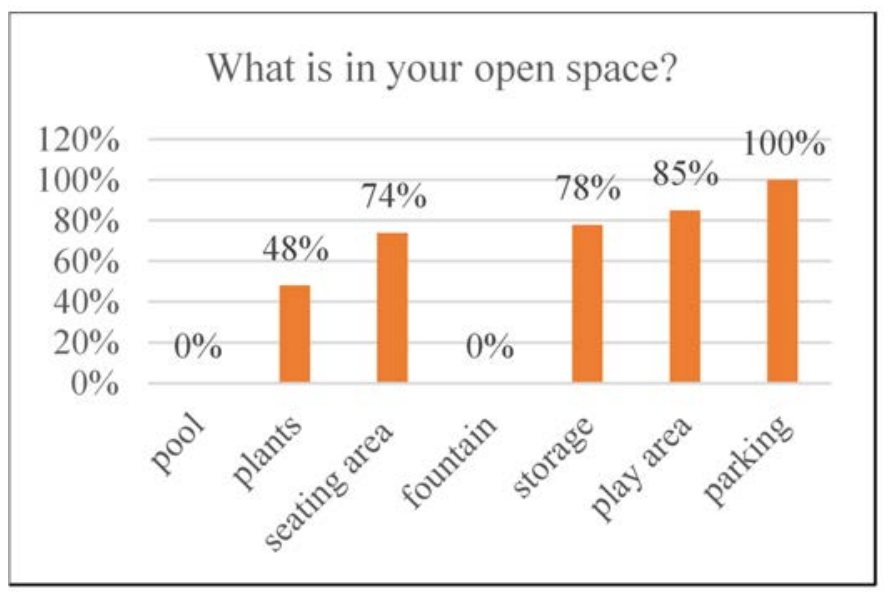

Figure 3: Usage type of open spaces.

78 percent, and 74 percent respectively. Plants are not common - just 48 percent have plants in their houses - while pools and fountains are non-existent. Therefore, when it comes to traditional houses, outdoor space cannot play the same role as internal space in terms of providing a comfortable, domestic place for families with an acceptable climate. 
As for the most popular time of the day to use open spaces, the survey showed that 81 percent preferred to use these areas in the afternoon while no one used them at noon due to the extreme heat. Therefore, most residents are using their outdoor open spaces for parking and for storage.

\subsubsection{Openings and balconies}

To the question "Who designed your house", 30 percent mentioned a contractor and 15 percent an architect. This might explain why the majority of windows are located on the hottest façades, which are in the east and west directions. As seen in Figure 4, there are approximately 100 windows on east façades and 94 windows on west façades.

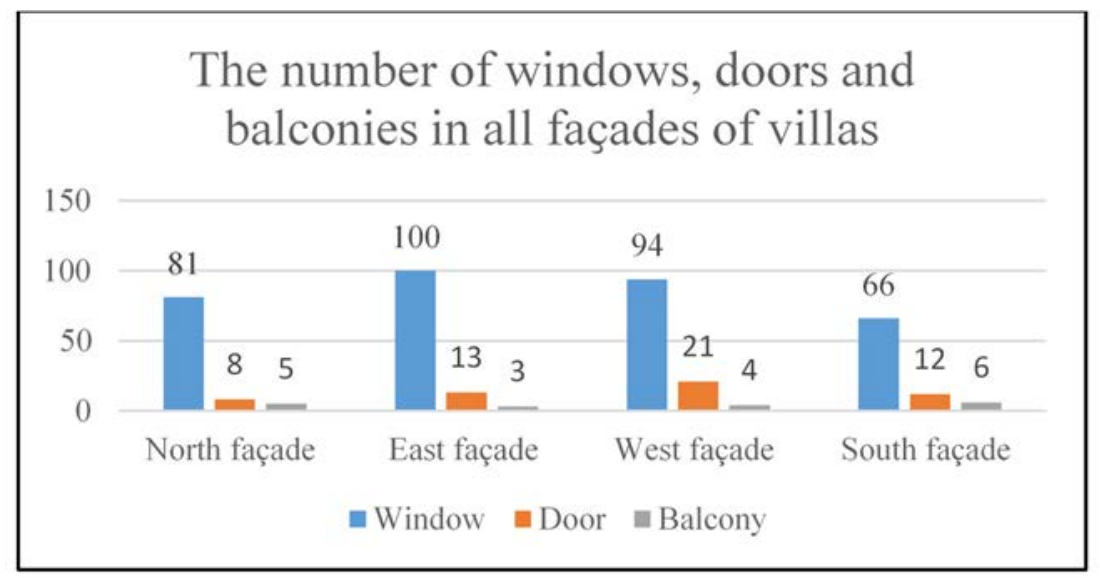

Figure 4: Number of openings and balconies in façades of private houses (villas).

\subsection{Cooling demand}

As shown in Figure 5, all residents of the flats and villas use air conditioning as a cooling mechanical system. Therefore, it was important to find out the BTU (British Thermal Unit), that is, the cooling capacity of air conditioning used in these buildings. The results were as follows: Sixteen respondents from the flats and 21 respondents from the villas said that their dwelling used 18,000 BTU, which is the most commonly attained level of cooling capacity for air conditioning. The second most commonly attained levels of cooling capacity were 24,000 and 26,000 BTU in the flats, whereas the second highest for the villas was 24,000 and 28,000 BTU in the villas. In addition, 30,000 BTU are used in villas (with 7 respondents) and none in flats. Therefore, the area of the house has a direct effect on the cooling capacity of the air conditioning.

As for the question "In which season(s) is the air conditioning system used?" the highest use of air conditioners is found throughout the summer season in all of the flats and villas. In the villas, however, the air conditioning is heavily used throughout the spring and autumn seasons, with 89 percent and 70 percent respectively, indicating an increase of air temperature during these seasons. 


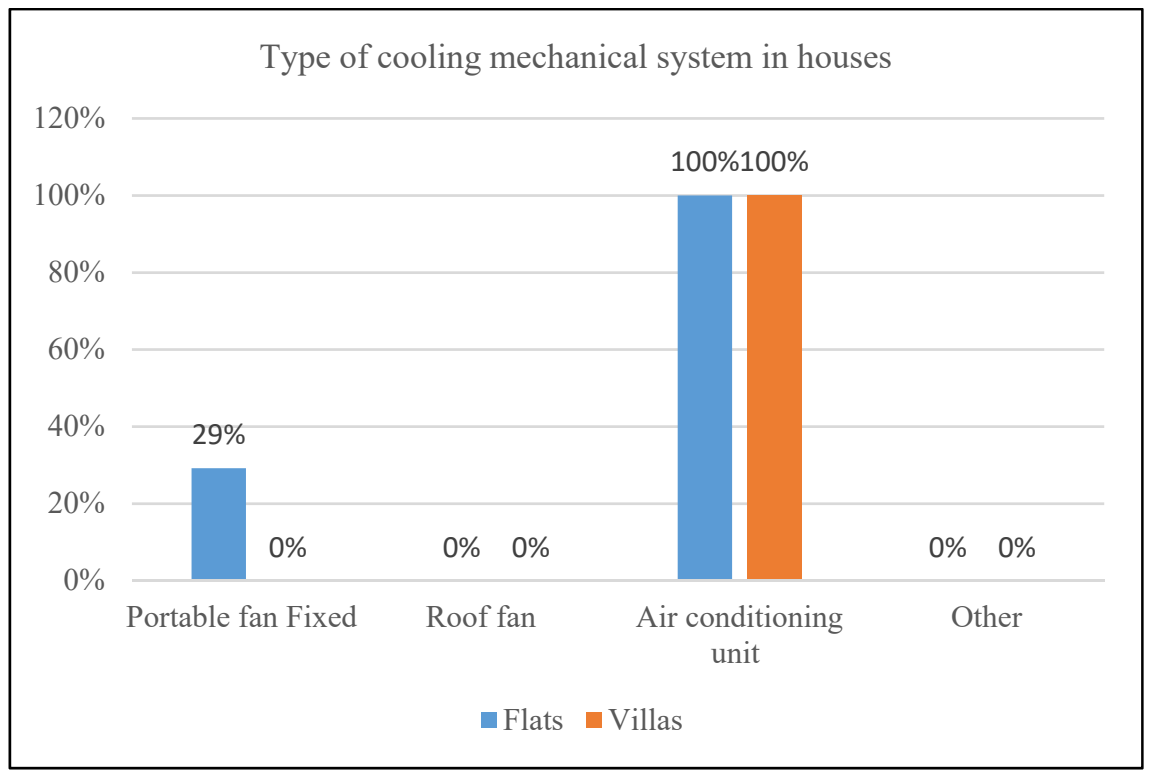

Figure 5: Type of cooling mechanical system in houses.

\section{Conclusions}

We have conducted a survey among residents of the city of Benghazi to find out the level of environmental comfort of their dwellings. After analysing the responses, it has been possible to draw some conclusions with regard to the qualities of traditional Islamic dwellings as compared to contemporary housing which follows the model of western architecture:

1. The traditional Islamic courtyard houses provide an acceptable indoor environment while preserving privacy. Their design principles could be applied to contemporary housing design. Accordingly, it is important to facilitate natural ventilation through the regulated air movement between the internal open spaces and the external small openings, providing maximum shading of direct and reflected sun radiation in the hot season.

2. Compared to contemporary housing, traditional Islamic houses use more outdoor spaces than inner spaces. Likewise, they use high and small openings instead of large glazed windows placed on exterior walls. As a result, there is an increase in the indoor temperature of modern houses, which makes the use of air conditioning necessary.

3. From the questionnaire results, it can be extrapolated that the majority of houses have outdoor spaces, with their main usage being for storage space.

4. It is important that architects have the responsibility to design houses, with the users contributing to that design. 
5. Due to the large increase in the use of air conditioning in private houses, in architects should consider using the traditional elements in contemporary houses, such as inner courtyards and small openings in the façades.

\section{References}

[1] El-Shorbagy, A., Traditional Islamic-Arab house: Vocabulary and syntax. International Journal of Civil \& Environmental Engineering IJCEE-IJENS, 10(4), pp. 15-20, 2010.

[2] Susilawati, C. \& Al Surf, M., Challenges facing sustainable housing in Saudi Arabia: A current study showing the level of public awareness. The 17th Pacific Rim Real Estate Society Conference, Bond University, Queensland, Australia, 2011.

[3] Al Sayyed, W., Contemporary Arab architecture: Space, form, and function. Lonaard Magazine, 2(7), 2012.

[4] Sharif, S.M., Zain, M.F.M. \& Surat, M., Concurrence of thermal comfort of courtyard housing and privacy in the traditional Arab house in Middle East. Australian Journal of Basic and Applied Sciences, 4(8), pp. 4029-4037, 2010.

[5] Mahgoub, Y., The re-emergence of the courtyard in Kuwaiti housing design, 2012. http://ymahgoub.blogspot.co.uk/2012/.

[6] Nabavi, F. \& Goh, A.T., Quality of home in Iran: The mismatch between design and lifestyle. Workshop: NHRDWS01, 2001. www.enhr2011.com/.

[7] Khalaf, R.W., Traditional vs. modern Arabian morphologies. Journal of Cultural Heritage Management and Sustainable Development, 2(1), pp. 2743, 2012.

[8] Ajaj, A. \& Pugnaloni, F., Re-thinking traditional Arab architecture: A traditional approach to contemporary living. International Journal of Engineering and Technology, 6(4), p. 286, 2014.

[9] Khoukhi, M. \& Fezzioui, N., Thermal comfort design of traditional houses in hot dry region of Algeria. International Journal of Energy and Environmental Engineering, 3(1), pp. 1-9, 2012.

[10] Leylian, M.R., Amirkhani, A., Bemanian, M.R. \& Abedi, M., Design principles in the hot and arid climate of Iran: The case of Kashan. Academic Research, 2(5), 2010.

[11] Edwards, B., Courtyard Housing: Past, Present and Future, Taylor \& Francis, 2006.

[12] Bekleyen, A. \& Dalkilic, N., The influence of climate and privacy on indigenous courtyard houses in Diyarbakır, Turkey. Scientific Research and Essays, 6(4), pp. 908-922, 2011.

[13] Al Aali, M., A House in Bahrain, 2006.

[14] Ahmed, K.G., A "fareej-in-the-sky": Towards a community-oriented design for high-rise residential buildings in the UAE. Open House International, 37(1), 2012.

[15] Gabril, N., Thermal Comfort and Building Design Strategies for Low Energy Houses in Libya: Lessons from the Vernacular Architecture, 2014. 
[16] Shawesh, E.M., The Changing Identity of the Built Environment in Tripoli City, Libya, 2000.

[17] General Electric Company of Libya (GECOL), Annual Report 2012. www.gecol.ly.

[18] Agll, A.A.A., Hamad, Y.M., Hamad, T.A. \& Sheffield, J.W., Study of energy recovery and power generation from alternative energy source. Case Studies in Thermal Engineering, 4, pp. 92-98, 2014.

[19] Mohamed, A.A., Towards More Sustainable Urban Forms in the City of Benghazi: A Study of Urban Fragmentation at the Neighbourhood Level, 2013.

[20] Al-Jamea, M., Towards social and cultural sustainability in the designs of contemporary Saudi houses. International Journal of Sustainable Human Development, 2(1), pp. 35-43, 2014.

[21] Almansuri, A.A., Climatic Design as a Tool to Create Comfortable, Energy-Efficient and Environmentally Wise Built Environment, Tripoli, Libya, 2010. 